\title{
Transhomens: masculinidades, políticas e vivências
}

\author{
Transmasculinidades: a \\ emergência de novas \\ identidades políticas e sociais. \\ ÁVILA, Simone.
}

\begin{abstract}
A transexualidade se fundamenta na náo concordância entre o sexo biológico e o gênero através do qual a pessoa deseja ser reconhecida. Falar de transexualidade implica na reflexão sobre o que é sexualidade para além das concepções biológicas, obrigandose a pensar nas vivências da sexualidade nos âmbitos privado e público, tanto como prática individual, como prática social e política. (Simone ÁVILA, Miriam GROSSI, 2010).
\end{abstract}

O livro Transmasculinidades: A emergência de novas identidades políticas e sociais é resultado da tese de doutoramento em Ciências Humanas da pesquisadora Simone Ávila pela Universidade Federal de Santa Catarina (UFSC). A autora, graduada em fisioterapia, teve contato com a temática da transexualidade quando trabalhou com Assistência Domiciliar Terapêutica a pessoas portadoras de HIV na cidade de Porto Alegre, em 1996. Entre seus pacientes estavam travestis profissionais do sexo ou usuárias de drogas. Em 2000 , já no Serviço de Atendimento Especializado em DST/AIDS, se deparou com outra forma de autoidentificação: as transexuais. Ao refletir sobre as dificuldades pelas quais as travestis e as transexuais passam e que pôde testemunhar, isso a despeito de sua organização política, questionou o que aconteceria com os transhomens (homens que ao nascer foram designados como sendo do gênero feminino), geralmente invisibilizados?

A autora explica que os termos mais utilizados para autoidentificação que encontrou foram FtM (Female to Male, feminino para masculino) e transexual masculino. Em seu trabalho optou pelo uso da palavra transhomem pelos seguintes motivos: por se tratar da uma tradução aproximada de transhomme, utilizado pela teórica queer MarieHélène Bourcier (2008); porque a palavra é um substantivo, algo que denomina os sujeitos, não um adjetivo, que os qualifica; e, por fim, para fugir de binarismos que ficariam implícitos na adjetivação homens trans/mulheres trans.

A obra é estruturada em cinco capítulos. O primeiro, "O Campo de pesquisa e suas complexidades", aborda questões relacionadas à entrada no campo de pesquisa, que se deu em grande parte através da internet, embora também através de eventos com temática LGBT (Lésbicas, Gays, Bissexuais, Transexuais, Travestis e Transgêneros). Inicialmente a pesquisa abarcaria apenas a região sul do Brasil, mas, por meio de redes sociais, como o Orkut e o Facebook, foi possível ampliála de forma a ter interlocutores de quase todas as regióes do país. Com o Youtube vieram perfis de usuários que postam seus vídeo-diários, especialmente aqueles que compartilham as mudanças ocasionadas pela ingestão de hormônios no processo FłM. Além disso, a criação da página "Sou transhomem... e daí?" - com conteúdo como notícias a respeito de transexualidade e transgeneridade, galeria de fotos, vídeos, grupos de apoio e informações sobre legislação - permitiu o contato de novos interlocutores, através de formulários para envio de mensagens privadas.

O trabalho de campo ocorreu entre 2009 e 2014 e envolveu trinta e três interlocutores, entre dezoito e cinquenta anos, todos transhomens. Em virtude de o contato inicial ter ocorrido através da internet, a escolaridade deles é alta. Todos possuem pelo menos Ensino Médio ou Técnico completo. Quinze possuem formação no Ensino Superior, um concluiu Mestrado e dois, Doutorado.

O segundo capítulo, "Você vira Freak Show", aborda questões relacionadas à produção de sujeitos generificados. Desde a infância, os sujeitos 
são lidos e identificados a partir de códigos específicos e, utilizando dispositivos presentes na sociedade farmacopornográfica, conforme aponta Paul Preciado (2008), conseguem construi vivências e corporalidades de acordo com o gênero com o qual se identificam. Conceitos de gênero são explorados, do performativo de Judith Butler (2010) ao tecnoecológico-político de Preciado (2008).

A relação com o próprio corpo e a forma como ele é interpretado por aqueles no entorno emerge nos relatos. Nem todos se sentem desconfortáveis em relação à sua genitália, mas a maioria dos interlocutores deseja remover ou já removeu as mamas. O título do capítulo diz respeito à fala de um dos participantes ao afirma que se você tem um comportamento masculino mas os seios aparecem sob sua camiseta, todos ficam olhando e você vira "Freak Show" (ÁVILA, 2014, p. 99).

Perpassam essa seção a apropriação do discurso biomédico e a discussão em torno da patologização da transgeneridade, muitas vezes utilizadas de forma estratégica pelas próprias pessoas trans, que fazem uso de instrumentos psico-médico-farmacológicos para acessar o sistema legal, que pode dar validade legislativa e/ou materialidade a suas vivências. Por fim, é discutida a falta de autonomia dos sujeitos em relação aos próprios corpos, uma vez que diversos procedimentos só podem ser realizados através de longo e custoso acompanhamento médico; por outro lado, o reconhecimento civi da identidade requerida só é possível através de cirurgia de transgenitalização, que nem todos desejam fazer.

No terceiro capítulo, "Questões privadas e públicas nos processos de autoidentificação trans", Ávila dedica-se aos relatos dos interlocutores $e$, através de histórias de suas infâncias e adolescências, chama atenção para o momento em que percebem a "diferença". O ambiente escolar enquanto mecanismo regulador, de acordo com Michel Foucault (1986), que marca e estabelece discursivamente diferenças de gênero, se faz perceber nas falas. Mas enquanto as etnografias a respeito de travestis trazem a questão da evasão escolar, o que se percebe nos relatos apresentados é o isolamento, a solidão e a busca por boas notas. Nas vidas adultas, há a procura por um corpo que reflita os desejos dos sujeitos, uma vez que, conforme a autora, a transexualidade, ao contrário da homossexualidade, "parece exigir uma exposição pública necessária para o reconhecimento de sua existência no gênero desejado" (ÁVILA, 2014, p. 139).
O capítulo quatro, "Transhomens brasileiros em um novo regime de visibilidade", aborda meios pelos quais os transhomens têm tornado visíveis suas trajetórias, seja através das mídias sociais ou de narrativas literárias ou cinematográficas. João W. Nery, por exemplo, lançou duas autobiografias: Erro de Pessoa (1984) e Viagem Solitária (2011). O primeiro livro trata de sua infância, do processo de transição iniciado aos vinte e sete anos, até os procedimentos cirúrgicos. Na segunda publicação ele discorre sobre sua vida adulta após a conclusão dessas etapas e sobre a paternidade, através da adoção.

Além dos livros de Nery, são citadas outras autobiografias, nacionais e estrangeiras, de pessoas transgêneras, como Christine Jorgensen: a personal autobiography, reconhecida como a primeira a ser publicada no mundo, em 1967. As publicações frequentemente abordam a dificuldade de se encaixar no corpo ou no papel que é esperado de seus autores, de acordo com o gênero que Ihes foi atribuído. A percepção da identidade trans, a hormonização, as cirurgias e as dificuldades que envolvem a transição também são objeto dos textos. Por fim, narrativas a respeito de relações amorosas e sexuais e a dificuldade de encontrar um parceiro ou uma parceira. As obras autobiográficas são apresentadas como pertencentes a um contexto social, com finalidades públicas e privadas e audiências múltiplas.

Outra história abordada é a de Sillvyo Lúccio Nóbrega, que protagonizou o documentário Olhe para mim de novo, dirigido por Cláudia Priscilla e Kiko Goifman, lançado em 2011 . Nóbrega entrou em contato com a pesquisadora através de seu site, indicando o filme. Trata-se de um road movie pelo sertão do Nordeste, em que Sillvyo sai da cidade de interior onde reside e, através da viagem, entra em contato com o desconhecido.

Para o estudo são utilizados, ainda, postagens em blogs que compartilham informações e experiências pessoais, além de vídeos em canais do Youtube, conforme mencionado anteriormente, nos quais transhomens exibem os resultados de mudanças corporais, como barbas que aparecem e vozes que alteram o timbre. Muitos também falam do passado e de como era viver como uma "mulher masculina". O compartilhamento de fotos de transhomens com corpos musculosos e a existência do "homem grávido" provocam questionamentos entre os interlocutores a respeito do tipo de masculinidade que é aceita nas comunidades.

A autora reflete que o campo de estudos de gênero e transgeneridade também se configura como um "espaço biográfico", 
perpassado pelas "narrativas de si mesmo" "representações de si", articulando discursos através da experiência de vida (ÁVILA, 2014, p. 150-151). Trabalha-se, aqui, com a ideia de que filmes, assim como as autobiografias, entrevistas, postagens em blogs e outras formas de narrativa também constituem esse espaço biográfico.

O capítulo final, "A emergência de transhomens brasileiros no movimento LGBT no Brasil", conta com um levantamento de grupos e institutos relacionados aos transhomens no Brasil, com seus respectivos históricos de atuação. Nele são abordadas particularidades sobre o movimento LGBT e a participação dos transhomens. De acordo com Ávila, enquanto na França, por exemplo, o movimento trans tem suas próprias reivindicações e lutas, atuando de forma autônoma, no Brasil o movimento LGBT une-se às militâncias de travestis, transexuais e tansgêneros, como uma tentativa de fortalecer o coletivo. Por outro lado, dessa forma, as lutas específicas do "T" não são contempladas e muitas vezes as pessoas trans são invisibilizadas nesse processo.

O capítulo possui um breve histórico da inclusão do "T" na sigla LGBT, bem como os debates que envolvem a participação de ativistas trans no movimento feminista e, no caso de transhomens, no movimento de lésbicas. 0 texto também apresenta o relato de um interlocutor que sempre foi ativista lésbica, mas que, após fazer a "transição de gênero", passou a ser visto como possível opressor ou agressor.

O trabalho de Simone Ávila possui um amplo corpus, que inclui filmes, sites, redes sociais, livros, blogs, além do contato com seus interlocutores. A revisão bibliográfica é rica, especialmente em se tratando de um tema ainda pouco pesquisado no Brasil e conta com uma escrita acessível e direta, amarrando de maneira eficaz teoria e campo. O fato de todos os interlocutores terem escolaridade alta é destacado pela própria pesquisadora, uma vez que o perfil de classe média pode não abranger todas as vivências e experiências possíveis. De toda forma, com tantas etnografias que abordam travestilidades e transfeminilidades, Transmasculinidades: a emergência de novas identidades políticas e sociais tem o importante papel de problematizar as especificidades dos transhomens, bem como de suas trajetórias e reivindicações.

\section{Referências}

ÁVILA, Simone. Transmasculinidades: a emergência de novas identidades políticas e sociais. Rio de Janeiro: Multifoco, 2014.

ÁVILA, Simone; GROSSI, Miriam. Maria, Maria, João, João: Reflexões sobre a transexperiência masculina. In: Anais Eletrônicos do Seminário Internacional Fazendo Gênero 9: Diásporas, Diversidades, Deslocamentos, 23 a 26 de agosto de 2010, Florianópolis. Disponível em: <http:// www.fazendogenero.ufsc.br/9/resources/anais/ 1278255349 ARQUIVO Maria,MariaJoao,Joao 040721010. pdf >. Acesso em: 09/12/2015.

BOURCIER, Marie-Hélène. "Technotesto: Biopolitiques des masculinités tr(s)ans hommes". Cahiers du Genre, n. 45, p. 59-84, jul/dez. 2008.

BUTLER, Judith. Problemas de Gênero: Feminismo e subversão da identidade. Rio de Janeiro: Civilização Brasileira, 2010

FOUCAULT, Michel. Vigiar e Punir: História da violência nas prisões. Petrópolis: Vozes, 1986.

PRECIADO, Paul. Testo Junkie: Sexe, drogue et biopolitique. Paris: Bernard Grasset, 2008.

Isabel Wittmann

Universidade Federal do Amazonas, Manaus, Amazonas, Brasi 